\title{
Editorial \\ Advances in Microstructural Characterization of Metals by EBSD
}

\author{
Sónia Simões ${ }^{1,2}$ (D)
}

Citation: Simões, S. Advances in Microstructural Characterization of Metals by EBSD. Metals 2021, 11, 1452. https: / /doi.org/10.3390/ met11091452

Received: 23 August 2021

Accepted: 9 September 2021

Published: 14 September 2021

Publisher's Note: MDPI stays neutral with regard to jurisdictional claims in published maps and institutional affiliations.

Copyright: (C) 2021 by the author. Licensee MDPI, Basel, Switzerland. This article is an open access article distributed under the terms and conditions of the Creative Commons Attribution (CC BY) license (https:/ / creativecommons.org/licenses/by/ $4.0 /)$.
1 Department of Metallurgical and Materials Engineering (DEMM), University of Porto, R. Dr. Roberto Frias, 4200-465 Porto, Portugal; ssimoes@fe.up.pt; Tel.: +351-22-041-3113

2 LAETA/INEGI, Institute of Science and Innovation in Mechanical and Industrial Engineering, R. Dr. Roberto Frias, 4200-465 Porto, Portugal

\section{Context and Scope of the Special Issue}

Electron backscattered diffraction (EBSD) is a material characterization technique that attracts many researchers to characterize different types of materials. This technique presents itself as an asset in the characterization of the materials since it presents an excellent resolution and the possibility of describing several microstructural aspects that are not possible with other techniques. Some of these microstructural characteristics can be the grain size with a high resolution, crystallographic orientation, texture, and aspects related to the texture and character of the grain boundaries, among others.

Sample preparation can be challenging, depending on the material and the purpose of the characterization. All recent advances in this area and the application of this technique are also essential.

In this context, this Special Issue aimed to include works on the application of EBSD to characterize metallic materials at different scales and present the most significant challenges encountered in the application of this technique, as well as its main applications and full potential in advanced materials characterization.

Finally, a review of the scientific advances in this field has been carried out through a selection of five original research papers (progress review and articles) on the impact of the EBSD in the microstructural characterization of the metals.

\section{Contributions}

Alateyah et al. [1] investigated the microstructural evolution and crystallographic texture of copper produced by equal channel angular pressing (ECAP) by EBSD. The as-annealed sample consisted of equiaxed grains with twins and a high density of high angle grain boundaries, while the ECAP samples shown a bimodal microstructure with a higher density of low angle grain boundaries. The ECAP samples also revealed a strong, simple shear texture. Mayo et al. [2] shown a combination of interrupted tensile tests with crystallographic characterization performed by means of EBSD, by analyzing the evolution of an intercritically deformed micro-alloyed steel. Kanetas et al. [3] performed a detailed microstructural characterization by the EBSD of Inconel 718 (IN718) Ni-based superalloy that was subjected to a delta-processing treatment (DP718) and, subsequently, deformed at high temperature. Gondo et al. [4] studied the evolution of texture in the thickness direction of the cylindrical cup, which was spun from a rolled aluminum sheet in 13 passes, using electron backscatter diffraction pattern analysis.

Since the EBSD has been attracting enormous interest in the microstructural characterization of metals in recent years, all its potentials were covered by Carneiro et al. [5]. This characterization technique has several advantages over conventional ones, since it allows for obtaining a wide range of characterization possibilities in a single method, which is not possible in others. The grain size, crystallographic orientation, texture, and grain boundary character distribution can be obtained by EBSD analysis. Despite the limited resolution of 
this technique (20-50 nm), EBSD is powerful, even for nanostructured materials. Through this technique, the microstructure can be characterized at different scales and levels with a high number of microstructural characteristics. It is known that the mechanical properties are strongly related to several microstructural aspects, such as the size, shape, and distribution of grains, the presence of texture, grain boundaries character, and the grain boundary plane distribution.

Funding: This research received no external funding.

Acknowledgments: The guest editor would like to thank all authors for submitting their excellent work to this Special Issue. Furthermore, thanks are given to all the reviewers for their outstanding work evaluating the manuscripts and providing helpful comments. The above collection of highquality papers would not be possible without this joint effort.

Conflicts of Interest: The author declares no conflict of interest.

\section{References}

1. Alateyah, A.I.; Ahmed, M.M.Z.; Zedan, Y.; El-Hafez, H.A.; Alawad, M.O.; El-Garaihy, W.H. Experimental and Numerical Investigation of the ECAP Processed Copper: Microstructural Evolution, Crystallographic Texture and Hardness Homogeneity. Metals 2021, 11, 607. [CrossRef]

2. Mayo, U.; Isasti, N.; Rodríguez-Ibabe, J.M.; Uranga, P. Analysis of Strain Partitioning in Intercritically Deformed Microstructures via Interrupted Tensile Tests. Metals 2021, 11, 112. [CrossRef]

3. Kañetas, P.J.P.; Calvo, J.; Rodriguez-Calvillo, P.; Marrero, J.M.C.; Antuñano, M.A.Z.; Guerrero-Mata, M.P. EBSD Study of Delta-Processed Ni-Based Superalloy. Metals 2020, 10, 1466. [CrossRef]

4. Gondo, S.; Arai, H.; Kajino, S.; Nakano, S. Texture Evolution of a Rolled Aluminum Sheet in Multi-Pass Conventional Spinning. Metals 2020, 10, 793. [CrossRef]

5. Carneiro, I.; Simões, S. Recent Advances in EBSD Characterization of Metals. Metals 2020, 10, 1097. [CrossRef] 